\title{
Prevalence and Pattern of Cancers among Adults Attending a Tertiary Health Institution in Lagos, Nigeria
}

\author{
Popoola.A.O* ${ }^{1}$, Omodele F.O ${ }^{2}$, Oludara M.A ${ }^{3}$, Ibrahim.N.A ${ }^{4}$, Igwilo.A.I ${ }^{5}$, \\ Makanjuola.S.B.L ${ }^{6}$ \\ ${ }^{1 \& 5}$ Oncology Unit, Department of Radiology, Lagos State University Teaching Hospital \\ ${ }^{2,3,4}$ Department of Surgery, Lagos State University Teaching Hospital \\ ${ }^{6}$ Department of Pharmacology, Lagos State University College of Medicine
}

\begin{abstract}
Cancer is an increasingly important public health problem in developing countries including Africa. The burden of cancer in Nigeria is unknown, mainly because of lack of statistics or under reporting.

The aim of this study is to determine the incidence and pattern of cancer distribution among patients attending the hospital and comparing with existing data.

This is a descriptive cross sectional study conducted among Cancer patients who attended the Oncology clinic of Lagos State University Teaching Hospital over the period between 2005 and 2011 and incidence rates were calculated.

Ethical approval was obtained from the Ethics Committee of the institution.

From the cancer registry of the institution, it was reported that 1315 cancer cases was recorded between 2005 and 2011; Male cancers accounted for 14.1\% while female cancers was $85.9 \%$.

Following the statistical analysis, it was found that Breast cancer topped the incidence chart with 974 patients (74.75\%). This was followed by colorectal Cancer and Prostate; Then, Ovarian, Bone, Occular, Endometrial, Lung, Nasopharyngeal, Gastric, bladder, parotid, oral and maxillary cancers in that order.

The broader outlook of this global burden ignites a drive towards intensive research aimed at reducing the current morbidity \& mortality statistic from this debilitating disease.

Keywords: Burden, Cancer, Incidence, Nigeria, ,Pattern
\end{abstract}

\section{Introduction:}

An individual's risk of developing cancer depends on many factors, including age, lifestyle and genetic makeup (1). From an estimated 12 million new cases and 7.6million deaths in 2008, the incidence of cancer worldwide is expected to rise to 26.4 million with 17 million deaths by 2030.Most of these new cases of cancer are expected to occur in the developing world, particularly India and China ${ }^{2}$.

Cancer is an increasingly important public health problem in developing countries including Africa $^{3}$.

The 10 most commonly diagnoses cancer in male and females in the UK in 2008 are Male-Prostate, Lung, colorectal, Bladder, Non Hodgkin lymphoma, malignant melanoma, oesophageal, kidney, stomach, leukaemia; Female-Breast, lung, colorectal, uterus, ovary, malignant melanoma, Non Hodgkins Lymphoma, Pancreas, kidney, leukemia. Just four cancers-breast, lung, colorectal and prostate account for over half (54\%) of the cancer burden in United Kingdom(1).

The burden of cancer in Nigeria is unknown, mainly because of lack of statistics or under reporting. In a study of cancer registry literature updated from all over the world, only $1 \%$ of the literature emanated from Africa compare to $34 \%$ and $42 \%$ from Europe and Asia respectively ${ }^{4}$. In the World Health Organisation bulletin, report No.804 of 1990, it was reported that over 50 percent of cancer victims live in poor nations like Nigeria which have less than 10 percent of the resources for cancer care and control.

Presently, there are 11 cancer registries in Nigeria, located in various tertiary hospitals and most of them are poorly funded. They all produce hospital-based data.

According to the US National Cancer Institute Epidemiology and End Results (SEER) database for the year 2008, the estimated cancer prevalence in the United States as at January $1^{\text {st }} 2008$ was $11,958,000 .^{4}$

The American Cancer Society predicts that approximately 1,690,000 new cancer cases will be diagnosed and 577,000 Americans will ultimately die of cancer in $2012 .^{5}$

A study carried out among Australians showed that compared to other Australians, indigenous Australians had much higher incidence of lung and other smoking-related cancers, cervix, uterus and liver cancer, but much lower incidence of breast, prostate, testis, colorectal, brain cancer, melanoma, lymphoma and leukaemia. ${ }^{6}$

Parkin et al reported that in indigenous Africans, 650,000 people of an estimated 965million are diagnosed of cancer annually and lifetime risk of dying from cancer in African women is 2 times higher than in developed countries. ${ }^{7}$ 
The World Health Organisation estimated incidence of cancer from all sites in 2002 for Nigeria was 90.7 and 100.9 per 10,000 for males and females respectively while mortality rates were 72.2 and 76 respectivelyGlobocan.6 This is comparable to 89.1 and 104.1/100,000 incidence for males and females and 72.2 and 79.6 crude mortality rates recorded for Ghana but much less than figures recorded for United Kingdom and USA. ${ }^{7}$ Generally, Cancer incidence in Nigeria appears low compared to developed countries which may not truly reflect the burden. ${ }^{7}$

The six most common cancers in Nigeria in descending order of frequency are breast, cervix, prostate, colorectal, liver cancer and Non Hodgkins Lymphoma and data obtained from various parts of the country show that cancer incidence is increasing with female cancers leading and increasing incidence has been attributed to lifestyle change and poor awareness about risk factors. ${ }^{7}$

The aim of this study is to determine the incidence and pattern of cancer distribution among patients attending the hospital and comparing with existing data.

\section{Method:}

Background: The study was carried out at the Oncology clinic of the Lagos State University Teaching Hospital, Ikeja, Lagos, Nigeria. The hospital is one of the two teaching hospitals in the State. It comprises several departments such as Surgery, Medicine, Paediatrics, Obstetrics \& Gynaecology, Radiology, etc.

Study Design: This is a descriptive cross sectional study conducted among Cancer patients who attended the Oncology clinic of Lagos State University Teaching Hospital over the period between 2005 and 2011.

Sampling Method: Identified registration data from all registered malignant primary cancers diagnosed between 2005 and 2011 were obtained from the Lagos State University Teaching Hospital Cancer Registry.

Data from the registries were combined to produce semi age adjusted incidence rate by sex and cancer status.

Incidence rates were calculated for all cancer combined (1 C D-10 codes C00-C96) and for specific cancer sites. Ethical approval was obtained from the Ethics Committee of Lagos State University Teaching Hospital.

Data entry and analysis were done using a statistical software package.

\section{Result:}

The total number of patients that presented with breast cancer during this period is $974,74.75 \%$ male patients accounted for $8(0.82 \%)$, while female patients accounted for 966 (99.18\%). (TABLE 1)

The second highest incidence is colorectal with a total of 92 patients (7\%). Males accounted for $57(61.9 \%)$ and females accounted for $35(3.19 \%)$.

This is followed by prostate with 42 patients $(3.19 \%)$.

The total number of patients with ovarian cancer is $38(2.8 \%)$.

Patients who presented with bone cancer during this period are 25 (1.90\%). Males accounted for $14(56 \%)$ while females accounted for $44 \%$.

A total of 24 patients presented with ocular malignancy. (1.82\%). $13(54.2 \%)$ are males and $11(45.83 \%)$ are females.

$19(1.44 \%)$ patients presented with endometrial carcinoma. $20(1.52 \%)$ patients presented with cervical cancer. A total of 19 patients presented with Liver cancer $(1.44 \%)$ with $9(47.4 \%)$ being males and $10(52.6 \%)$ females. The number of patients with Lung cancer is $16(1.21 \%) 16$ with male accounting for $7(43.75 \%)$ and female accounting for $9(56.25 \%)$

A total of 15 patients $(1.14 \%)$ presented with nasopharyngeal carcinoma. While $13(86.67 \%)$ of the cases were observed in male; $2(13.3 \%)$ were observed in females.

8 patients $(0.60 \%)$ presented with Gastric cancer. Male and female were each $50 \%$.

6 patients presented with bladder cancer among whom 2 are males $(33.3 \%)$ and $4(66.7 \%)$ are females.

$6(0.46 \%)$ presented with oral cancer among whom 5 are males $(83.3 \%)$ and $1(16.7 \%)$ is a female, while 2 $(0.15 \%)$ patients presented with maxillary cancer.(TABLE $3 \&$ Fig 1$)$

There are total of 1,315 cancer cases recorded between the periods of 2005 -2001. Male cancer accounted for $14.1 \%$ while female cancer was $85.9 \%$.

IV. Figures \& Tables

Table 1: Table showing the sum of all the cases by Gender Outcome

\begin{tabular}{|l|l|l|l|l|l|}
\hline & N & Minimum & Maximum & Sum & Mean \\
\hline MALE & 16 & 1 & 43 & 185 & 11.56 \\
FEMALE & 15 & 1 & 966 & 1130 & 75.33 \\
\hline
\end{tabular}


Prevalence And Pattern Of Cancers Among Adults Attending A Tertiary Health Institution In Lagos,

Table 2: Showing the Percentage Distribution of Various Cancer Cases .

\begin{tabular}{|l|l|l|}
\hline Cancer & Incidence & Percentage of Incidence (\%) \\
\hline Stomach & 8 & 0.61 \\
\hline Uterus & 19 & 1.44 \\
\hline Rectum & 29 & 2.21 \\
\hline Prostrate & 42 & 3.19 \\
\hline Ovary & 38 & 2.89 \\
\hline NASOPHARYNX & 15 & 1.14 \\
\hline Mouth & 6 & 0.46 \\
\hline Liver & 19 & 1.44 \\
\hline Eye & 24 & 1.83 \\
\hline Cervix & 20 & 1.52 \\
\hline Bone & 25 & 1.90 \\
\hline Bronchus & 16 & 1.22 \\
\hline Breast & 983 & 74.75 \\
\hline Bladder & 6 & 0.46 \\
\hline ACCESSORY SINUS & 2 & 0.15 \\
\hline colon & 63 & 4.79 \\
\hline Total & 1,315 & 100 \\
\hline
\end{tabular}

Table 3: Showing the Distribution of Various Cancer Cases by Gender

\begin{tabular}{|c|c|c|}
\hline Cancer & Sex & No of Cases \\
\hline \multirow[t]{2}{*}{ Stomach } & Male & 4 \\
\hline & Female & 4 \\
\hline Uterus & Female & 19 \\
\hline \multirow[t]{2}{*}{ Rectum } & Male & 14 \\
\hline & Female & 15 \\
\hline Prostrate & Male & 42 \\
\hline Ovary & Female & 38 \\
\hline \multirow[t]{2}{*}{ NASOPHARYNX } & Male & 13 \\
\hline & Female & 2 \\
\hline \multirow[t]{2}{*}{ Mouth (oral cavity) } & Male & 5 \\
\hline & Female & 1 \\
\hline \multirow[t]{2}{*}{ Liver } & Male & 9 \\
\hline & Female & 10 \\
\hline \multirow[t]{2}{*}{ Eye } & Male & 13 \\
\hline & Female & 11 \\
\hline Cervix & Female & 20 \\
\hline \multirow[t]{2}{*}{ Bone } & Male & 6 \\
\hline & Female & 5 \\
\hline \multirow[t]{2}{*}{ Bronchus } & Male & 7 \\
\hline & Female & 9 \\
\hline \multirow[t]{2}{*}{ Breast } & Male & 17 \\
\hline & Female & 966 \\
\hline \multirow[t]{2}{*}{ Bone (Skull) } & Male & 8 \\
\hline & Female & 6 \\
\hline \multirow[t]{2}{*}{ Bladder } & Male & 2 \\
\hline & Female & 4 \\
\hline ACCESSORY SINUS & Male & 2 \\
\hline \multirow[t]{2}{*}{ colon } & Male & 43 \\
\hline & Female & 20 \\
\hline
\end{tabular}




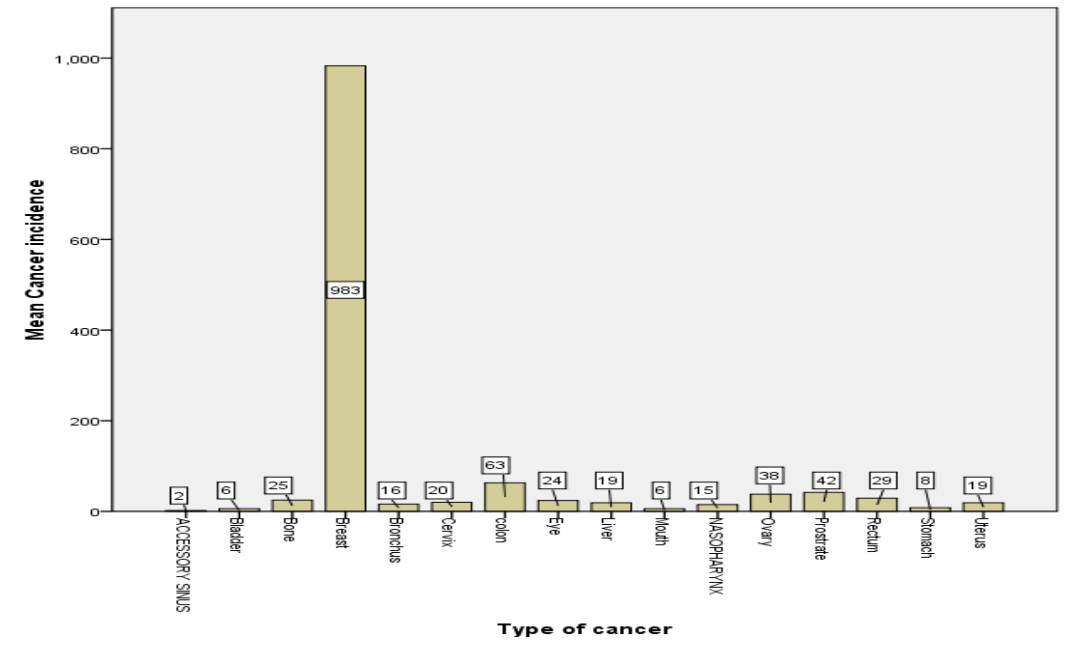

Fig 1: Graphical representation of the distribution of the type of cancer by their Mean cancer incidence

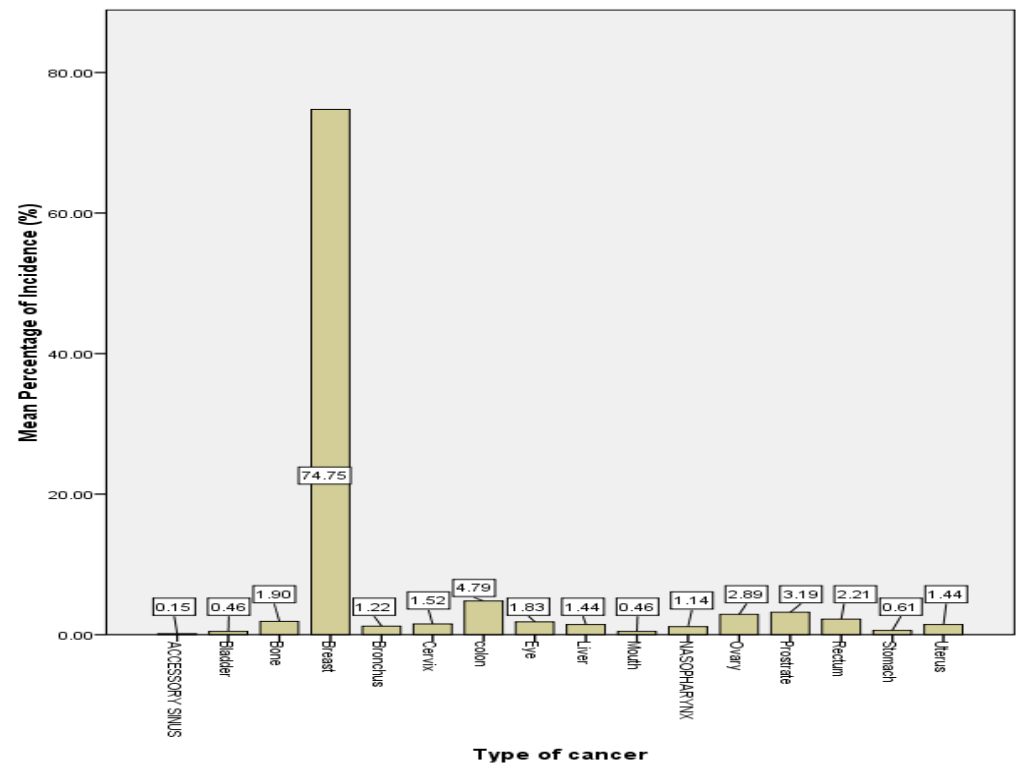

Fig 2: A graphical representation of the distribution of the type of cancer by the Mean percentage of incidence

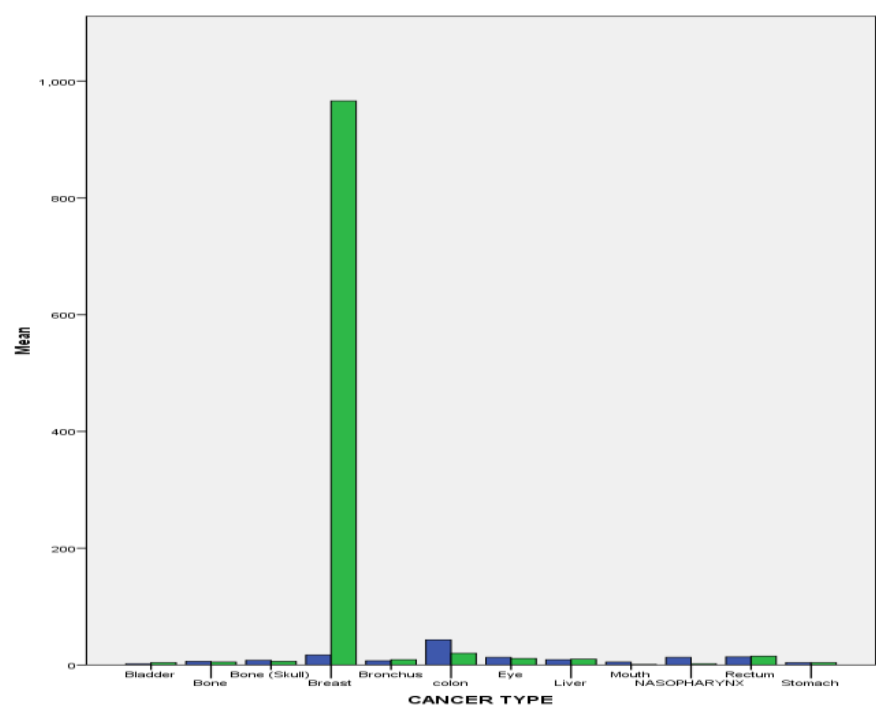

름mater

Fig 3: A graphical representation showing the distribution of the type of cancer by their various mean 


\section{Discussion:}

From the cancer registry in Lagos State University Teaching Hospital, it was reported that 1315 cancer cases was recorded between 2005 and 2011; Male cancers accounted for 14.1\% while female cancers was $85.9 \%$.

It is worthy to note the high incidence of breast cancer amongst cancer cases recorded, 974(74.75\%), male patients accounted for $8(0.82 \%)$, while female patients accounted for $966(99.18 \%)$. From the distribution of cancers seen at the morbid anatomy in Lagos University Teaching Hospital in 2007, Breast cancer was found to have the highest percentage 38\%; Also from the relative frequency of the six most common cancers in Ibadan; Breast cancer is the most frequently encountered with 41.8 between 1981-1995.

Global statistics show that the annual incidence of Breast cancer is increasing and this is occurring more rapidly in countries with previous low incidence rates (8). It has been reported that Breast cancer represents $10 \%$ of all cancers diagnosed annually and constituted $22 \%$ of all new cancers in women(8).

North America and Europe has been regarded as areas of higher breast cancer incidence, there has been a marked increase in breast cancer incidence in traditionally low incidence areas as women adopt a 'western' lifestyle, and more women seek medical care at hospitals $(9)$

In Nigeria, the incidence has doubled from 15.3 per 100,000 in 1976 to 33.6 per 100,000 in 1992(2). Studies now show that breast cancer is now the most common female malignancy, having overtaken cervical cancer (9). Unlike in high income countries where mortality rates have steadily declined over time as a result of earlier detection, more favourable breast cancer stage distribution and improved treatment, the situation in most medically underserved communities is still bleak. Reasons adduced for the differences in mortality rates include advanced stages at presentation, worse biologic behavior, poor treatment facilities and poor patient acceptance of recommended treatments, which has been attributed to ignorance, superstition, self-denial, fear of mastectomy and unavailability of treatment facilities (9) Expert opinion suggests that earlier discovery and treatment would favourably impact mortality rates from breast cancer(9).

Apart from the high incidence of breast cancer, there is also high incidence of colorectal cancer. The epidemiological pattern of the disease varies markedly between different populations group [10].

Colorectal cancer is the third most common malignancy in both men and women worldwide [11] and the second most frequent cause of death in the Western Europe and America [11]. In Africa, this disease was considered to be rare but this is no longer true [12]. The relative infrequency in Black Africa may be attributed to the young age of the population; shorter transit time of faeces, high fibre diet and rarity of precancerous conditions such as Familial Adenomatosis polyposis, ulcerative colitis and Crohns disease [13]. However, the molecular pathophysiology remains similar throughout the world [14].The incidence of colorectal cancer begins to rise at age 40 and peaks between ages 60 and 75 years [15]. In Caucasians, it peaks at the age of 70years. In a study, $57 \%$ were over 70 years while an incidence of $4 \%$ was found among young people [11]. In Africa on the average, patients were $10-15$ years younger and one-third were 40 years and below [12].

This is followed by Gynaecological cancer, carcinoma of the cervix and ovarian cancer. From the details from various cancer registries across countries, there is a high incidence of gynaecological cancers with carcinoma of the cervix leading which has been attributed to poor awareness about the risk factors, change in lifestyle. This can also be due to the fact that screening participation is generally low as is the compliance with follow up for abnormalities detected. Worldwide, however, both incidence and mortality from cervical cancer are second only to breast cancer, and in parts of the developing world, cervical cancer is the major cause of death in women of reproductive age. ${ }^{\underline{2}}$ This geographical disparity is related to the absence of effective screening programs, as epidemiologic and biological studies have not shown significant differences in tumor biology in countries with high rates of cervical cancer.

Prostate cancer accounted for 42 (13.19\%) of cancer recorded in our registry.

Current data from most part of the country show it to be the $3^{\text {rd }}$ most common cancer except in Calabar where a very high figure was recorded for prostate cancer as the most common for $34.7 \%$ of all cancers. Earlier report from that center between 1979-88 had recorded $28.6 \%$ of all male cancers. The increase in incidence has been attributed to introduction of PSA screening test which enable earlier diagnosis of cancer. The geographical distribution varies; the highest incidence occurs in Western countries and the lowest incidence is in Asia. Agespecific mortality rates have fallen slightly in both the USA and the UK, perhaps related to better treatment rather than screening because the UK has no organised screening programme (16)

Other cancers presented include liver cancer, accounting for 19 (1.44\%) of cancers recorded, with a relatively even distribution between males (47.3\%) and females (52.6\%). Liver cancer was earlier reported to be the most common male cancer in Nigeria until recently when it was overtaken by prostate cancer. It is the most common cause of liver disease in Nigeria accounting for between $29.3 \%-64 \%$ of all liver biopsies in several studies (7) and the $2^{\text {nd }}$ or $3^{\text {rd }}$ most common cause of cancer in males. A significant number of liver cancer cases are associated with liver cirrhosis, commonly caused by alcoholism, Hepatitis B, Hepatitis C, fatty liver disease; with the most prevalent in Nigeria being the Hepatitis B virus(7). 
Bone cancer cases were reported at $25(1.90 \%)$. The incident of bone tumour is variable but globally low. Previous studies defining the frequency of bone tumour in a retrospective study from 1977 to 2000 showed an incidence of $0.53 \%$ in all cancer cases in Ibadan. Our findings show an incidence of $1.90 \%$ for bone cancer, still considered low as observed in other developing countries (17). Nasopharyngeal carcinoma is another uncommon type of tumour. In Nigeria the prevalence is equally low but mortality is very high (18). 15 (1.14\%) cases were reported in our registry between 2005 and 2011.

Lung cancer accounted for 16 (1.21\%) of cancers reported in our registry. Previous reports suggest that the incidence rate for lung cancer remains low in West Africa, although reports are suggestive of a steady rise (19, 20). Cigarette smoke is globally linked to lung cancer. In addition, environmental pollutants in urban air, water, sewage treatment wastes and food materials have also been associated with lung cancer (21). In Nigeria, this is compounded by various hydrocarbons that are largely present in the atmosphere and are originated mainly from transportation, heat and power generation, refuse burning, industrial processes, and oil contamination (22).

\section{Conclusion:}

Cancer is an emerging public health problem especially in developing country like Nigeria, with adoption of behaviors and life style associated with economic development such as smoking, unhealthy deity and physical inactivity couple with aging and growth of the population. Hence a well-coordinated cancer control programme is essential through public education to prevent cancer, screening programmes to facilitate early diagnosis and the need for high quality population based cancer registry for better understanding of the cancer burden and cancer control planning.

\section{Acknowledgement:}

We wish to acknowledge and appreciate Mr. Rueben, the records officer at the Cancer registry who aided with the data collection and collation.

\section{References}

[1]. Cancer Research UK 2011 April 2011.

[2]. Akarolo-Anthony S.N, Ogundiran T.O, Adebamowo C.A. Emer.ging breast cancer epidemic: evidence from African. Breast Cancer Res. 2010; 12(4): S8-11

[3]. Farmer P, Frenk J, Knaul FM, Shulman LN, Alleyne G, Armstrong L, et al: Expansion of cancer care and control in countries of low and middle income: a call to action. Lancet 2010,376:1186-1193.

[4]. Howlader.N.,Noone..A.M,Krapcho.M,et al(2011);SEER Cancer Statistics Review;1975-2008 SEER data Submission

[5]. Wikipedia-Epidemiology of Cancer

[6]. Zhang.X,Condon.J.R,Rumbold.A.R.,Cunningham.J.,Rode.D.M (2011);Estimating Cancer Incidence in Indigenous Australians;Aust N.Z.J.Public Health;35(5);477-85

[7]. Fatimah Abdulkareem (2009);Epidemiology and Incidence of Common Cancers in Nigeria;Cancer Reg \& Epid Workshop April '09

[8]. Hanan.M.,Ola.A.,Hala.K.(2009); Impact of a health education intervention program about breast cancer among women in a semiurban area in Alexandria,Egypt;J.Egypt Public Health Asooc;vol 84;No.1\&2

[9]. Stanley.N.C.A.,Ochonma.A.E.Eric.C.I.(2011);Acceptance and adherence to treatment among breast cancer patients in Eastern Nigeria;The Breast;Elsevier;s51-s53

[10]. Schottenfeld D, ed. The epidemiology of cancer: an overview.1981;47:1095-108

[11]. Naader SB, Archampong EQ. Cancer of the colon and rectum in Ghana: A five year prospective study of Ghana Medical School, Accra. BJ of Surg. 1994;81:456-459.

[12]. Adesanya AA, Darocha-Afodu JT. Colorectal Cancer in Lagos; A critical review of 100 cases. The Nig Postgraduate Med Journal. 2000;7(3).

[13]. Badoe EA et al, ed.; Malignant tumours of the colon and rectum. In: Badoe EA et al., eds. Principles and Practice of Surgery, 3rd edition, 670

[14]. Yawe KT, Bakari AA, Pindiga UH, Mayun AA. Clinicopathological pattern and challenges in the management of colorectal cancer in Sub-saharan Africa. Journal of Chinese Clinical Medicine. 2007;2(12):688.

[15]. Berkow R, ed. The Merck manual of Medical Information, Home Edition. Colorectal cancer, 1997:553-554.

[16]. Jim Barber and John Staffurth Prostate cancer: practical clinical oncology www.cambridge.org/9780521618168

[17]. Omololu AB, Ogunbiyi JO, Ogunlade SO, Alonge TO, Adebisi A, Akang EE. Primary malignant bone tumour in a tropical African University teaching hospital. West Afr J Med 2002;21:291-3

[18]. $\underline{\text { BS Alabi }}{ }^{1}, \underline{\text { KB Badmos }^{2}}, \underline{\text { OA Afolabi }}{ }^{1}, \underline{\text { MO Buhari }}{ }^{2}, \underline{\text { S Segun-Busari }}{ }^{1}$ Clinico-pathological pattern of nasopharyngeal carcinoma in Ilorin, Nigeria. Year : 2010 | Volume : $13 \mid$ Issue : 4 | Page : 445-448

[19]. Niang A, Bonnichon A, Ba-Fall K, Dussart C, Camara P, Vaylet F, Mbaye PS, L'Her P, Sane M, Margery J: Lung cancer in Senegal. Med Trop(Mars). 2007;67(6):651-6

[20]. Bah E, Parkin DM, Hall AJ, Jack AD, Whittle H: Cancer in the Gambia, 1988-97. Br J Cancer 2001;84(9):1207-14

[21]. Waterhouse J, Muir C, Shanmugarantman K, Powell J (1976). Cancer incidence in five continents. ARC Scientific Publication.3: 15.

[22]. Adembamowo CA, Ajayi OO (2000). Breast cancer in Nigeria. West.Afr. J. Med., 19: 179-191. 